\title{
The Fox gene family in Xenopus laevis: FoxI2, FoxM1 and FoxP1 in early development
}

\author{
BARBARA S. POHL, ANTJE RÖSSNER and WALTER KNÖCHEL* \\ Abt. Biochemie, Universität UIm, UIm, Germany
}

\begin{abstract}
We here describe the sequences and expression patterns of three new Fox (fork head box) transcription factors in Xenopus laevis embryos. xIFoxl2, another member of subclass $\mathrm{I}$, is maternally transcribed. Zygotic transcripts are first detected during neurulation and become localised to the dorsal part of epibranchial placodes. XIFoxM1 like XIFoxP1 are the first members of subclasses $\mathrm{M}$ and $\mathrm{P}$ described in Xenopus. Both genes are maternally expressed and transcripts are found during early cleavage stages in the animal blastomeres. XIFoxM1 is strongly upregulated during neurula stages and transcripts are localised in the neuroectoderm. Later, expression is found in the spinal cord, the rhombencephalon, the retina and in the branchial arches. XIFoxP1 is activated during organogenesis and is mainly expressed in the brain, head mesenchyme and in the splanchnic layer of the lateral plate mesoderm.
\end{abstract}

KEY WORDS: X. laevis, embryogenesis, fork head/winged helix factor, expression pattern

Fox (fork head box) transcription factors are involved in various signalling pathways and cell fate decisions throughout development. According to conserved amino acid residues at distinct positions within the winged helix domain, these factors are categorised into the subclasses $A$ to $Q$ (Kaestner et al., 2000). While for the mouse and human species, Fox family members from all subclasses have been reported, in the South African clawed frog, Xenopus laevis, currently only the subclasses $A$ to $L$ are known. Here we report the sequence and initial characterisation of two additional Xenopus laevis Fox gene family members, $x / F o x M 1$ and $X I F O X P 1$ and add $X I F O X / 2$ as a new member to the already existing subclass I. We describe the full length cDNAs encoding these proteins and investigate the temporal and spatial expression patterns of corresponding genes by RT-PCR and by whole mount in situ hybridisations.

\section{Results and Discussion}

\section{xIFoxI2}

The Foxl subclass is already known in different organisms to contain several members and has recently been analysed regarding the phylogenetic relationship inside the subclass based on the zebrafish members (Solomon et al., 2003). By searching in EST data bases we have found an IMAGE-clone (4084049), which covers the complete translated region of a Foxl subclass member in Xenopus laevis. Referring to the suggested terminology regard- ing subclass I (Solomon et al., 2003), this clone is preliminarily designated as XIFoxI2, even if the true orthologue relationship inside this subclass remains to be elucidated. The complete sequence of the IMAGE-clone has been determined and deposited under EMBL accession number AJ868112. Starting 78 bp in front of the start codon, the complete cDNA sequence comprises 1537 $\mathrm{bp}$ and a poly $(\mathrm{A})$ tail. The translated region encompassing $1107 \mathrm{bp}$ gives rise to a protein of 369 amino acids, with the fork head domain located between amino acids 115 and 224. The predicted amino acid sequence is aligned to the pseudo-allelelic variants XIFoxI1a and xIFoxl1b (Lef et al., 1994) as well as to the close relative xIFoxl1c (Pohl et al., 2002) (Fig. 1). While xIFoxl2 is 44\% identical to xIFoxl 1 a and $46 \%$ to xIFoxI1b, it shows $48 \%$ identity to xIFoxI1c. However, conservation within the winged helix domain exhibits $84 \%$ and $86 \%$ identity between xIFoxl2 compared to xIFoxI $1 a$ and to $x I F o x \mid 1 b$, respectively and $88 \%$ to xIFox $1 \mathrm{c}$. Interestingly, all so far identified members of subclass I, $x / F o x / 1 a / b, x / F o x / 1 c$ and $x I F O x / 2$, show characteristic and different temporal expression patterns (Fig. 2) (Pohl et al., 2002). Starting with high amounts of maternal transcripts, $x$ IFox/2 expression decreases rapidly during early cleavage stages. Zygotic expression starts at neurulation and continues at low levels at stage 39. The $x / F o x / 1 a / b$ genes, which exhibit identical patterns (Lef etal., 1994), are strongly upregulated

Abbreviations used in this paper: Fox, fork head box.

\footnotetext{
*Address correspondence to: Dr. W. Knöchel. Abteilung Biochemie, Universität UIm, Albert-Einstein-Allee 11, D-89081 UIm, Germany. Fax: +49-731-502-3277. e-mail: walter.knoechel@medizin.uni-ulm.de
} 
during the early blastula stage reaching a maximum number of transcripts at the gastrula stage. Thereafter, the amount of transcripts declines during neurulation, with low levels even detected at stage 40. Finally, $x / F o x / 1 c$ starts expression at the late gastrula stage and transcripts constantly accumulate during later embryogenesis (Pohl et al., 2002). Thus it is evident that the genes belonging to subclass I are subject to different regulatory mechanisms and that different developmental stages are associated with the expression of distinct XIFoxI proteins.

Results obtained by whole mount in situ hybridisation confirm the temporal patterns as determined by RT-PCR. High amounts of XIFox/2 transcripts are present at early cleavage stages in the animal half of the blastomeres (Fig. 3A, B). Zygotic expression is exclusively found in the placodes of the head (Fig. 3C). In contrast to the placodal expression of $x$ IFox/1a (Fig. 3F) and XIFox/1C (Fig. $3 \mathrm{G}), x / F o x / 2$ is only expressed in the dorsal part of the epibranchial placodes (for an overview see Schlosser and Northcutt, 2000). As shown by a transverse section (Fig. 3D), stained XIFoxI2 positive cells are located between the mesodermal foregut tissue and the more dorsal head mesenchyme. A horizontal section demonstrates that $x /$ Fox/2 is expressed within a restricted region located near the tip of the first, second and third visceral pouch (Fig. 3E).

\section{XIFoxM1}

FoxM1 was originally isolated in a search for proteins that are phosphorylated during M-phase (Westendorf et al., 1994) without having been identified as a winged helix factor. After the isolation of the complete cDNA from mouse (Genbank accession number: NM_008021, Korver et al., 1997a) and the human orthologue (Genbank accession number: NM_202002, Ye et al., 1997; Korver et al., 1997 b; Yao et al., 1997) it became clear, that the expression of FoxM1 (also named MPP2, Trident, FKHL16, HFH-11 and WIN) is strictly correlated to proliferating cells.

XIFoxM1 was originally identified in form of the incomplete ESTclones BJ618321 and XL058d22. Screening of a stage 30 cDNA library led to the isolation of an incomplete cDNA overlapping with $\mathrm{XL058d22.} \mathrm{With} \mathrm{5'-primers} \mathrm{derived} \mathrm{from} \mathrm{BJ618321} \mathrm{and} \mathrm{3'-primers}$ derived from our cDNA, the complete coding sequence could finally be amplified from a reverse transcribed stage 30 RNA. The cDNA contains 2762 bp and a poly (A) tail (deposited under EMBL accession number AJ853462). The protein is encoded by $2277 \mathrm{bp}$, thus comprising 759 amino acids. The fork head domain is located at the $\mathrm{N}$-terminal half in between amino acids 251 and 360 . Figure $4 \mathrm{~A}$ shows an alignment of the Xenopus sequence to the human and mouse orthologues. While the human and mouse proteins share $79 \%$ identity, the identities between xIFoxM1 and human
1 MNTFGQQPTN . . . . . . PH. . AQDLLDMAMYCDHF SLYHQQQNQQL

1 MNP . VQQPAQHKCPASSLNPPHPKRAQEAPDMGLYCDNF . MYQOHNL . . .

1 MNP. VQQPAQHRSPASLLHLPHPKRAQEAPDMGLYCDNF . MFSOHQL . . .

1 MNS . IHLPSNQRTSASSLHQHHPKGAQEASEMAVY CDNF SMYHQONL . . .

38 PQRPAAPPATGYGLN. EYSSPPSSPYLWLNGPAINSSPYLNGGSGSPYFP 46 ...HPSHRATNFS IG. DFT . HQANPYLWLGGPGVNNSPSYSPTP. APYIP 46 ..HPSQRAPNFS IGGEFT. PPANPYLWLGGPGMNNAPNYSPAP. APY IP 47 . . HSSQRAPNYGIG.DYA.PPTNPYLWLGGPGVSNSSSYLHGNNPTSFM

7 AGYGGGQRQFLPPSSGFGVADFPWLSIPNOADLLKMVRPPYSYSSLIAMA 90 PAFSAPQRQFLANSAAFGGADLGWMSAASOEELLKRVRPPYSYSALIAMS 91 SAFSAPQRHFMANSAAFGGADLGWMSAASQEELLKMVRPPYSYSALIAMA 92 SPSYGSQRQFLSNSSSFCGTDLSWLSVASQEELLKVVRPPYSYSALIAMA

37 IQNTPDKKLTLSQIYNYVAENFPFYKKSKAGWQNSIRHNLSLNDCFKKVA IQNATDKRLTLSQIYQYVAENFPFYKKSKAGWQNSIRHNLSLNDCFKKMP
1 IQNASDKRLTLSQIYQYVAENFPFYKKSKAGWQNSIRHNLSLNDCFKKMP X.1.FOXI2 187 RDDHDPGKGNYWTLDPNCEKMFDNGNFRRKRKRKSESVGAGFDEDSNEDK X.1.FOXI1a 190 RDENDPGKGNYWTLDSNCEKMFDNGNFRRKRKPKSETNNIKIA. . KREED X.1.FOXI1b 191 RDENDPGKGNYWTLDSNCEKMFDNGNFRRKRKPKSESNNAKIA. . KRDED

X.1.FOXI2 237 KPLALKSLGSDSPQGASVLEQSSYDAA. PEGKSKAPVGSAAQDSSHCFTN X.1.FOXI1a 238 н...VSPKGKESPPMITP.SSPKELSPTGHSKCPSPPTVT...YTPCLTN X.1.FOXI1b 239 н...LNPKGKESPPMITPSSSPEVLSPTGHSKSPSPPTVT...YTPCLTN X.1.FOXI2 286 FASNMNALINNRTPROFTAGRGDFSNSRHY . LAELTSCPIPSPQISAPQ x.1.FOXI1a 281 FIGSMTAVDSATMNRQGPLGLLNELSQRNLNGLSSFISGSAVD. QSPEHQ X.1.FOXI1b 283 FIGSMTAVDSATMNRQSPLGLLNELSQRNITGLSSFISGSAVD.QSSEHQ X.1.FOXI2 334 T.......GSKVPCYP.SKQQNNLCTSVMNPFGLNHL.YSREG.EV (369aa) X.1.FOXI1a 330 DSSLFYNRSPYYSSLP.TSNOKOPPYLQQLHPQQSPL.YQ..GRY (370aa) X.1.FOXI1b 332 DNSLFYNRSPYY....T.NQKQPHFLQQLHPQQPPL.YQ..GRY (367aa)

Fig. 1. FoxI2 sequences. Alignment of the predicted amino acid sequence of Xenopus laevis (x.I.) Fox12 to Foxl1a, Foxl1b (Lef et al., 1994) and Fox/1c (Pohl et al., 2002). Identical residues are shown in blue. The fork head domain is shaded in gray.

FOXM1 (36\%) and mouse Foxm1 (37\%) are rather low. However, this low degree is mainly due to a stretch of deviating amino acids following the fork head domain. In this context it should be noted that several mammalian splice variants are described (Yao et al., 1997). Adjacent to this region, the rate of identity is significantly higher and that of the winged helix domains is even $84 \%$ (see Fig. $4 A$, calculated by DIALIGN, Morgenstern et al., 1998). To determine the temporal expression pattern of XIFoxM1 in Xenopus embryos, RNAs of different developmental stages were analysed by RT-PCR. As shown in Fig. 2, maternal gene transcription yields high amounts of RNA in early cleavage stages, but transcripts are rapidly degraded until the blastula stage. Zygotic expression of XIFoxM1 starts during neurulation and transcripts persist and accumulate until the end of organogenesis.

The spatial expression was determined by in situ hybridisation (Fig. 5). Transcripts are found in the animal half at early cleavage stages (Fig. 5A), but are absent from gastrula stage embryos. During neurulation, expression is observed in the neural folds and, later, in the spinal cord as well as in the eye field (Fig. 5B, C). This localisation becomes even more prominent at stage 22, when transcripts demarcate the region of the eye (Fig. 5D). Thus, it can 


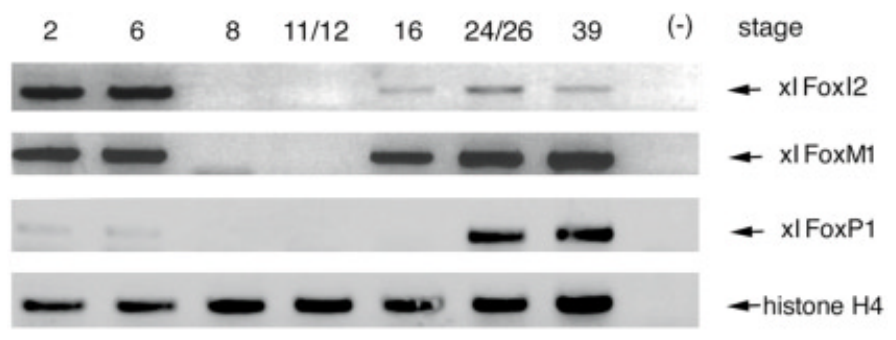

Fig. 2. Temporal expression of $x I F o x \mid 2, x I F o x M 1$ and $x I F o x P 1 . ~ R T-P C R$ for XIFoxI2, XIFoxM1 and XIFoxP1 was performed with RNAs of different developmental stages. (-) indicates a negative control in the absence of RNA. Histone H4 was used as internal control.

be concluded that $X$ IFoXM1 is involved in early stages of eye formation. During tailbud stages, XIFoxM1 expression is still restricted to the neuroectoderm, predominantly to the hindbrain, the eye and the spinal cord (Fig. 5E). With ongoing development, expression is also found at lower levels in the branchial arches (Fig. $5 \mathrm{~F})$. Sections of embryos at stage 35 reveal distinct expression of XIFOXM1 in the rhombencephalon, in the eye retina but not the in forming lens and in the branchial arches (Fig. $5 \mathrm{G}-\mathrm{I}$ ). While in mouse development Foxm1 was found to be ubiquitously localised in all cell types during proliferation, its expression is downregulated when cells enter terminal differentiation (Korver et al., 1997a; Ye et al., 1997). In adult human and mouse tissues, FoxM1 is predominantly found within the thymus and testis and, at a lower extent, in intestine, liver and lung. Interestingly, a Foxm1 knock out mouse was found to be post-natally lethal due to a failure in development of the myocardium. Both for hepatocytes and myocytes, polyploidy was observed in combination with a dramatic increase in DNA content (Korver et al., 1998). Human FOXM1 is localised on chromosome 12p13. Chromosomal abnormalities of this region are known from several tumors which were initially explained by the cyclin dependent kinase inhibitor $\mathrm{p} 27^{\mathrm{kip} 1}$ localised in close proximity (Korver et al., 1997b). However, it has recently been found that FoxM1 itself is an important part of the precise machinery ensuring the correct progression through the cell cycle. This is achieved via a direct regulation of cyclin B1 and D promoters by FoxM1, in association with a diminished expression of p27 ${ }^{\text {Kip1 }}$ (reviewed in Costa et al., 2003).

\section{XIFoxP1}

The subclass $P$ of Fox transcription factors gained special interest, because FOXP2 was found to be associated with language disorders in humans (Lai et al., 2001). By sequence comparisons with great apes, FOXP2 was suggested to be an important target of selection during recent evolution in humans (Enard et al., 2002). FOXP1 was isolated in search for a protein known to be involved in several human tumors (Banham et al., 2001). Members of the FoxP subclass are also of interest, because these proteins contain a zinc-finger and a leucine-zipper located Nterminal to their fork head domain. For the first time in case of Fox proteins, FoxP factors are not only able to bind as heterodimers to DNA, but were shown to interact with each other due to these motifs (Wang etal., 2003; Li etal., 2004). XIFoxP1 was originally identified by the IMAGE-clone 3747208 . However, this clone encodes only the C-terminal part of the protein. Further database searches for sequences encoding the $\mathrm{N}$-terminal part led to additional EST clones (e.g. BE679963) which were used to elongate the Xenopus FoXP1 sequence. Finally, the complete coding sequence could be amplified by RT-PCR from stage 30 RNA. The XIFoxP1 cDNA sequence encompasses 1968 bp starting 54 bp in front to the start codon. It contains 180 bp of the $3^{\prime}$-UTR and, additionally, a poly(A) tail (deposited under EMBL accession number AJ853463). Since the EST-clone contains a stop codon in front of the translation start site, the derived amino acid sequence is shorter than those listed for mammals (homo sapiens Genbank accession number: NM_032682; mus musculus Genbank accession number: NM_053202). However, it should be mentioned that different isoforms with varying start sites are also reported for mice (Wang etal., 2003). Moreover, translation start site of the zebrafish FoxP1 (www.ensemble.org/ ENSDART00000023619) and, interestingly, also of the closely related FoxP2 gene in human (NM_014491) were uniformly determined to the respective start codon as we have found for XIFoxP1. The open reading frame of $X I F O x P 1$ contains 1734 bp encoding 578 amino acids. The fork head domain is located within the C-terminal half, a rather unusual feature for a Fox protein. The alignment of FoxP1 protein sequences of $X$. laevis, human, mouse and zebrafish is shown in Fig. 4B. Both on DNA and amino acid level, FoxP1 shows the highest homology
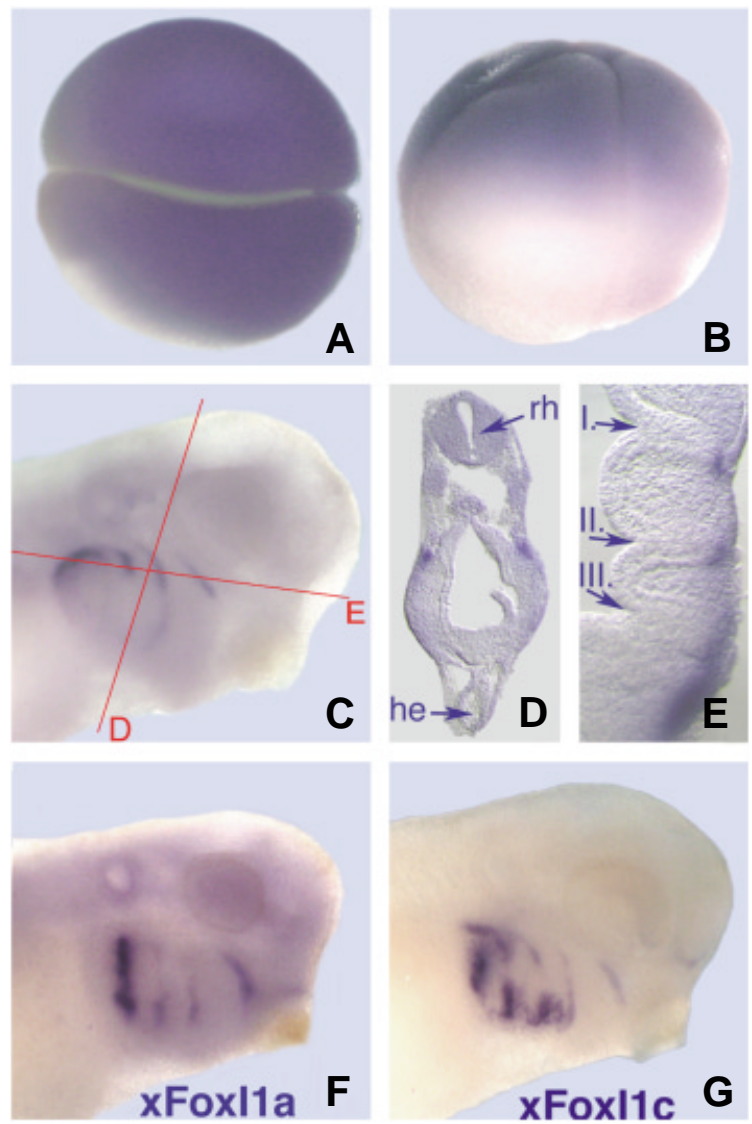

Fig. 3. Whole mount in situ hybridisation of $x$ IFoxl2. (A) 2-cell stage, animal view; (B) 4-cellstage, lateral view; (C) stage 35, the red lines denote sections shown in (D,E) which are transverse and horizontal sections respectively, through the dorsal epibranchial placodes; (F) stage 35 stained for XIFoxl1a; (G) stage 34 stained for XIFoxl1c. he, heart anlage; rh, rhombencephalon; I., II., III., first, second and third visceral pouches. 
A

X.1.FOXM1 1 MRTSPRRPLILKRRKLSLPHODATPCPGASEQGKAAMMKTANLPEQTLAH h.s.FOXM1 1 MKTSPRRPLILKRRRLPLPVQNAPS.$\ldots \ldots \ldots \ldots \ldots \ldots \ldots \ldots \ldots$ m.m.FOXm1 1 MRTSPRRPLILKRRRLPLPVQNAPS,$\ldots \ldots \ldots \ldots \ldots \ldots \ldots \ldots$

X.1.FOXM1 51 ELEDMAPKSKADQETPGQNEGGDTLGQSLAPTMRLPSNPPQSCPEDIPGE h.s.FOXM1 26 ETSEEEPKRSPAQOESNOAEASKEVAESNSCK............ m.m.FOXm1 26 ETSEEEAKRSPAQPKPAPAQASQEVAESSSCK.............

X.1.FOXM1 101 PSGVRIMGHPTMADAQLVIIPSQSNVQSIIQALTARGKEQG..GPNKYII h.s.FOXM1 59 PAGIKIINHPTMPNTQVVAIPNNANIHSIITALTAKGKESGSSGPNKFII m.m.FOXm1 59 PAGIKIINHPTTPNTQVVAIPSNADIOSIITALTAKGKESGSSGPNRFIL

X.1.FOXM1 149 ISSESAIQTQAWHQGPQI...... KEEECVNSQSEATCISKQKPTGNSRK h.s.FOXM1 109 ISCGGAP.TOPPGLRPOTOTSYDAKRTEVTLETLGPKPAARDVNLPRPPG m.m.FOXm1 109 ISSGG.PSSHPS...QPOAHSSRDSKRAEVITETLGPKPAAKGVPVPKPPG

X.1.FOXM1 193 AKHROEEO. ..........LNASLSNIOWLGNMSSESLGOYSIKEEOEDI h.s.FOXM1 158 ALCEQKRETCADGEAAGCTINNSLSNIQWLRKMSSDGLGSSIKQEMEEK m.m.FOXm1 156 APPRQRQESYAGGEAAGCTLDNSLTNIQWLGKMSSDGLGPCSVKQELEEK

X.1.FOXM1 232 ENQIPECAKMEEEPQSFPDPQWPLSVTERPPYSYMALIQFAINSTPRKRU h.s.FOXM1 208 ENCHLEQRQVKVEEPSRPSA SWONSVSERPPYSYMAMIQFAINSTERKRM m.m.FOXm1 206 ENCHLEQNRVKVEEPSGVSTSWODSVSERPPYSYMAMIOFAINSTERKRM

X.1.FOXM1 282 TLKDIYTWIEDHFPYFKHVAKPGWKNSIRHNLSLHDMFVRESEANNKVSY h.s.FOXM1 258 TLKDIYTWIEDHFPYFKHIAKPGWKNSIRHNLSLHDMFVRETSANGKVSF
m.m.FOXm1 256 TLKDIYTWIEDHFPYFKIAKPGWKNSIRHNLSLHDMFVRETSANGKVSF

x.1.FOXM1 332 WTIHPQANRCLTLDQVFKTASPMSPADNEP....QKKMIPDIRKSFQSAA h.s.FOXM1 308 WTIHPSANRYLTLDQVFKPLDPGSPQLPEHLESQQKRPNPELRRNMTIK m.m.FOXm1 306 WTIHPSANRYLTLDQVFKPLEPGSPQSPEHLESOOKRPNPELHRNVTIKT

X.1.FOXM1 378 CASNKE, RKMKPLLPRVNSYLIPVHFPVAOP.VLLPALE. . PYAFGAES h.s.POXM1 358 ELPLGARRKMKPLLPRVSSYLVPIOFPVNOSLVLOPSVKVPLPLAASLMS m.m.Foxm1 356 EIPLGARRKMKPLLPRVSSYLVPIQFPVNQSLVLQPSVKVPLPLAASLMS

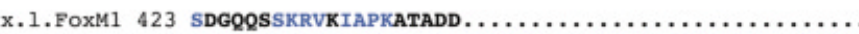
h.s.FOXM1 408 SELARHSKRVRIAPKVLIAEEGIAPLSSAGPGKEE. LLFGEGFSPLLPV m.m.FOXm1 406 SELARHSKRVRIAPKVLISSEGIAPLPATEPPKEEKPLLGGEGLLLLPI

X.1.FOXM1 $443 \ldots \ldots \ldots$. GESPKHLGLCSVKEEP.... DISN ...LKCEDLFQC... h.s.FOXM1 457 OTIKEEEIOPGEEMPHI.ARPIKVESPPLEEWPSPAPSFKEESSHSWEDSS m.m.Foxm 1456 OSTKEEEMOPEEDIAHLERPIKVESPPLEEWPSPCASLKEELSNSWEDSS

x.1.FOXM1 $472 \ldots \ldots \ldots \ldots \ldots \ldots \ldots \ldots \ldots \ldots \ldots \ldots \ldots \ldots \ldots \ldots \ldots$ KRVSSRRKOQLLPPHSE h.s.FOXM1 507 QSPTPRPKKSYSGLRSPTRCVSEMLVIQHRERRERSRSRRKOHLLPPCVD m.m.FOXm1 506 CSPTPKPKKSYCGLKSPTRCVSEMLVTKRREKREVSRSRRKOHLQPPCL

X.1.FOXM1 490 EPELVLPESIASDSGLDTDFSFIQDASANPNQNLTSHPTQNCPSNVTQEG h.s.FOXM1 557 EPELLFSE.GPSTSRWAAELPFPADSSDPASO $\ldots \ldots \ldots \ldots \ldots$

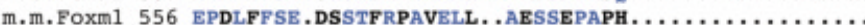

X.1.FOXM 540 LLHLTHDGPSYLTOVSSSHFTQDDPCQFTKDDTFYFTQDNPIQLTODEDY

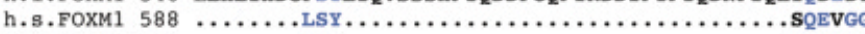

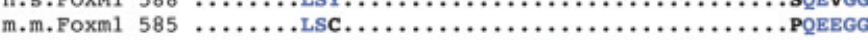

X.1.FOXM1 590 TFKTPIKEHFSKPTTSSTPSKPTDTGLLQPWESETSLPRDPVLDFSPVRI h.s.FOXM1 597 PFKTPIKETLPISSTPSKSVLPR.TPES..WRL.TPPAKVGGLDFSPVQ m.m.FOXm1 594 PFKTPIKETLPVSSTPSKSVLSRD, PES, . WRL.TPPAKVGGLDFSPVRT

X.1.FOXM1 640 POGSTFTPFKDNLGTLSFGDTPFKDFGIFGSPONLLNALSPASSPLLRL h.s.FOXM1 643 SOGNSD.PLPDPLGLMDLSTTPLOSAPPLESPORLLSSEPLDLISVPFGN $\mathrm{m}$.m.Foxm1 640 PQGAFG.LLPDSLGLMELNTTPLKSGPLPSPRELLNSEPFDLASDPFGS

X.1.FOXM1 690 S.PCVSRQQKRCSKELQV.GASANRSLLEGLVLDTVDDSLSKILLDISFS h.s.FOXM1 692 SSPSDIDVPKPGSPEPQVSGLAANRSLTEGLVLDTMNDSLSKILLDISFP $\mathrm{m} . \mathrm{m}$. Foxml 689 PPPPHVEGPKPGSPELOIPSLSANRSLTEGLVLDTMEDSLSKILLDISFP

$\mathrm{X}$.1.FOXM1 738 GMEEGNGLEVDGVWSQFLPEFK

$(759 a a)$
$(763 a a)$ h.s.FOXM1 742 GLDEDPLGPDNINWSOFIPELO m.m.FOXm1 739 GLEEDPLGPDINWSOFIP

(757aa)

\section{B}

x.1.FoxP h.s.FOXP1 m.m.Foxpl d.r.FOXP1

F........................MATPQVITPQQMQQIL QQQV MMOESGSETKSNGSAIONG. (+78aa) SVAMOTPQVITPQQMOOILOOOV MMESGSETKSNGSAIONG (+108aa) SVAMATPOVITPOOMOOILOOOV ........

X.1.FOXP1 21 LTPQQLOVLLOQOQALML. OQQLOEFYKKOQEQLOLOLLOQOHAGKOPKE h.s.FOXP1 121 LSPQQLOVLLOQQQALMLOQQQLOEFYKKOQBQLOLOLLOQOHAGKOPKE m.m.FoXp1 151 LSPQQLQVLLQQQQALML. QQQLQEFYKKQQEQLQLQLLQQQHAGKOPKE d.r.FOXP1 21 LSPQQLQLLQQQQALMLQQQQLQEFYKKQQEQLHLQLIQQQHGSKQ (+50aa)

x.1.FOXP1 70 QQQQQQQVATQQLAFQOQLLQMOQLOQOHLLTLQRQGLLSIQPGQPTLPLO h.s.FOXP1 $171 \ldots$... QOQVVATQOLAFQOQLLOMOQLOQOHLLSLORQGLLTIOPGQPALPLO

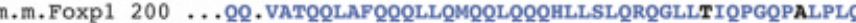
d.r.FOXP1 121 QSKSRQVSAQQLAFQQQLLQVQQLQQQHLLSLQRQGLLSIQPNQ.TLPLH

X.1.FOXP1 120 SLAQGMIPAELQQLWKEVTGSHTADDVVCNNHST. .LDLSTTCVSSTAOP h.s.FOXP1 218 PL.AOGMIPTELOOLWKEVTSAHTAEETTGNNHSS...LDLTTTCVSSSAPS $\mathrm{m} . \mathrm{m}$. FOXP1 246 PLAQGMIPTELQQLWKEVTSAHTAEETTSSNHSS..LDLTSTCVSSSAPS d.r.FOXP1 167 TLTQGMIPAELQQLWKEVTNSPVKEENSVTNNGHRGLDLSS...PSPVPI X.1.FOXP1 168 KTSLLLNSOASTNGOASVLTLKRESSSHEEY.THNHPLYGHGVCKWPGC h.s.FOXP1 266 KTSLIMNPHASTNGQLSVHTPKRESLSHEEH. PHSHPLYGHGV m.m.FOXPl 294 KSSLIMOTPHASTMOOLSVHTPKRESLSHEEH. PHSHPLYGHOVCK d.r.FOXP1 214 K...NH.NOHGSTNGOYISHSLKREGSTLDDHSPHSHPLYGHGY .1.FOXP1 217 zinc-finger $\Downarrow$ l leucine-zipper h.s.FOXP1 315 AVCEDFQSFLKHLNSEHALDDRSTAQCRVO m.m.Foxp1 343 AVCDDFPAFLKHLNSEHALDDRSTAQCRVO d.r.FOXP1 261 AVFEDFQSFLKHLNNEHALDDRSTAOCRVD CtBP-binding h.s.FOXP1 365 DILAHVISTEPKMAPOPLNLUSSVTLSKSASEASPO.SLPHTPTTPTAP $\begin{array}{ll}\mathrm{h} . \mathrm{S} \text {.FOXP1 } & 365 \\ \mathrm{~m}, \mathrm{~m} \text {.FOXP1 } & 393\end{array}$ m.m.FOXP1 311 DOMHLHVISTEPKPTPQPLNLVSNVTLSKTAPAASPPLSLPQTPTTPTAP

X.1.FOXP1 316 LTPITQGPSVITTTSIHNVGPIRRRYSDKYNIPISS. DFAQNQEFYKNAE h.s.FOXP1 414 LTPVTQGPSVITTTSMHTVGPIRRRYSDKYNVPISSADIAQNQEFYKNAE m.m.FOXP1 442 LTPVTQGPSVITTTSMHTVGPIRRRYSDKYNVPISSADIAQNQEFYKNAE d.r.FOXP1 361 LTPLSOTHSVITPTSLHSVGPIRRRYSDKYMMPISP.DIVONKEFYMNAE

X.1.FOXP1 365 VRPPFTYASLIROGILESPEKOLTLNEIYNWFTRQFAYFRRNAATWKNAV h.S.FOXP1 464 VRPPFTYASLTROATLESPEKOLTLNEIYNWFTRMPAYFRRNAATWKNAV m.m.FOXP1 492 VRPPFTYASLIRQAILESPEKQLTLNEIYNWFTRMFAYFRRNAATWKNAV d.r.FOXP1 410 VRPPFTYASLIRQAILESPEKQLTLNEIYNWFTRMFAYFRRNAATWKNAV x.1.FOXP1 415 RHILSLHKCFVRVENVKGAVWTVDEMEFQKRRPQKISGSPTLIKNIOTSH h.s.FOXP1 514 RHNLSLHKCFVRVENVKGAVWTVDEVEFQKRRPOKISGNPSLIKNMOSS $\mathrm{m}$.m.FOXP1 542 RHNLSLHKCFVRVENVKGAVWTVDEVEFOKRRPOKISGNPSLIKNMOSS d.r.FOXP1 460 RHNLSLHKCPVRVENVKGAVWTVDELEFOKRRPOKISGSPALVKNIHTT

X.1.FOXP1 465 AYCSPLSAALOASMAENSLPLYTTASMGNPALNSLANAIREDLNGVMEHT h.S.FOXP1 564 AYCTPLNAALOASMAENSIPLYTTASMGNPTLGNLASATREELNGAMEH $\mathrm{m} . \mathrm{m}$. FOXp 1592 AYCTPLNAALOASMAENSIPLYTTASMGNPTLGSLASAIREELNGAMEHT d.r.FOXP1 510 GYGPALSAAFQASMAEN. IPLYTTASIGSPTLNSLASVIREEMNGAMDHG

X.1.FOXP1 515 SSNGSDSSPGRSPQGMHQVHVKEEPLDHDDNDGPLSLVTTANHSPDFDR h.s.FOXP1 614 NSNESDSSPGRSPMQAVHPVHVKEEPLDPEEAEGPLSLVTTANHSPDFDH m.m.Foxp1 642 NSNESDSSPGRSPMQAVHPIHVKEEPLDPEEAEGPLSLVTTANHSPDFDH d.I.FOXP1 559 NSETSDSSPGRSPL
X.1.FOXP1 565 DRDYEDDPYNDDME h.s.FOXP1 664 DRDYEDEPUNEDME m.m.FOXP1 692 DRDYEDEPVNEDME $\begin{aligned} & (777 \mathrm{aa}) \\ & (705 \mathrm{aa})\end{aligned}$ d.r.FoxP1 $\quad$............ (572aa)

Fig. 4. FoxM1 and FoxP1 proteins. (A) Alignment of the predicted amino acid sequence of Xenopus laevis (x.I.) FoxM1 with human (h.s.) FOXM1 and mouse (m.m.) Foxm 1. (B) Alignment of the predicted amino acid sequence of XIFoxP1 with human (h.s.) FOXP1, mouse (m.m.) Foxp1 and zebrafish (d.r.) FoxP1. Identical residues are shown in blue. The fork head domain is shaded gray. The green box shows the position of the Gli-like zinc-finger with the relevant cysteine and histidine residues denoted by arrows, the red box marks the leucine-zipper, the magenta box represents the CtBP-binding side.

between different species, that to our knowledge was ever reported for Fox genes. XIFoxP1 protein is $86 \%$ identical to its mouse and human orthologues and $70 \%$ identical to zebrafish FoxP1. Both the fork head domain (grey) and the zinc-finger motif (green) are highly conserved. The latter was found to be closely related to the first zinc-finger found in Gli-proteins (Shu et al., 2001). Furthermore, the leucine-zipper that is localised directly adjacent to the zincfinger and a binding site for the transcriptional co-repressor CtBP1 (Li et al., 2004) are also found to be conserved. Fig. 2 shows the temporal expression pattern of XIFoxP1. Low levels of maternal transcripts are present, but disappear before gastrulation. Zygotic transcription starts at stage 26 and continues throughout embryo- 

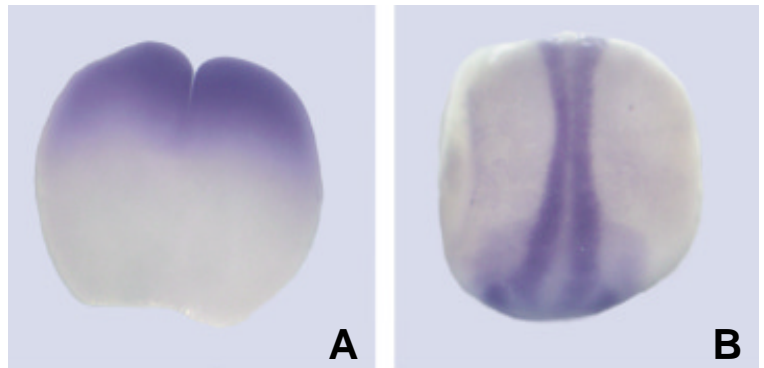

A

B
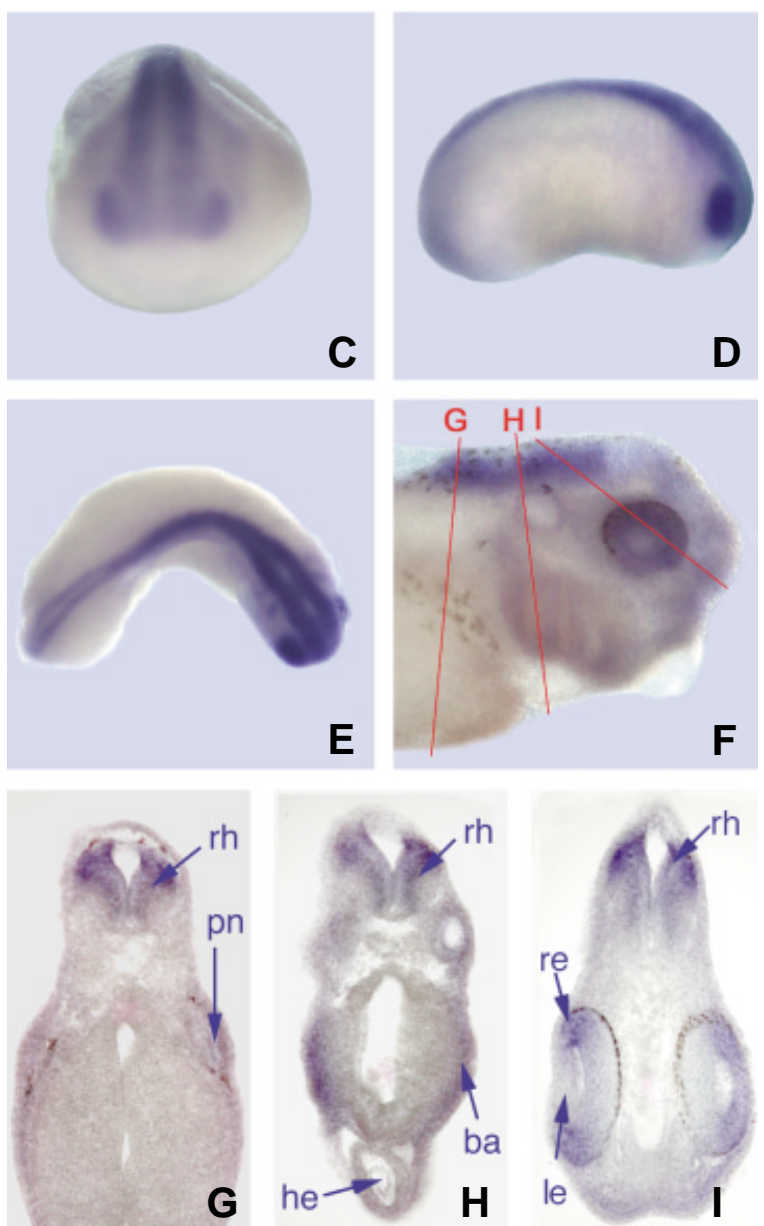

Fig. 5. Whole mount in situ hybridisation of xIFoxM1. (A) 2-cell stage, lateral view; (B) stage 16, dorsal view, anterior to the bottom; (C) stage 19, anterior view; (D) stage 22, lateral view; (E) stage 26, dorsal view; (F) stage 35; in (D-F), anterior is to the right. Red lines in (F) denote sections shown in (G-I). (G) Transverse section revealing XIFoxM1 expression in the rhombencephalon; (H) transverse section demonstrating additional staining of the branchial arches; (I) horizontal section of the head with staining of the retina, anterior is to the bottom. ba, branchial arches; le, lens; he, heart; pn, pronephros; rh, rhombencephalon.

genesis. In situ hybridisations reveal the presence of XIFoxP1 transcripts in the animal blastomeres of early cleavage stages (Fig. $6 \mathrm{~A})$. At tailbud stages, XIFoxP1 expression is visible in regions of the brain, eyes and the splanchnic mesodermal layer of the lateral plate mesoderm surrounding the gut (Fig. 6B,G). At stage 35, $\mathrm{XIFoxP} 1$ is expressed within the lens of the eye, in distinct regions of the head mesenchyme and the area anterior to the gut (Fig.
$6 \mathrm{C}, \mathrm{F})$. In the brain the anterior most staining is restricted to the outer region of the mesencephalon (Fig. 6E). With ongoing development additional expression is found in the curling gut (Fig. 6D). This corresponds to the in situ analyses performed in mice, where Foxp1, besides its expression in the lung, is also described in the developing central nervous system and in the intestine (Shu et al., 2001; Tamura et al., 2003). Thus, the relationship between the mammalian and Xenopus FoxP1 genes is not only reflected by sequence homology but also by similar expression patterns.

\section{Experimental Procedures}

RT-PCR, in situ hybridisation and handling of Xenopus embryos was done according to standard procedures (for more details see: Pohl and Knöchel, 2001). Developmental stages were determined according to Nieuwkoop and Faber, 1967.

The IMAGE-clone 4084049 was commercially obtained by RZPD (Deutsches Resourcenzentrum für Genomforschung $\mathrm{GmbH}$, Berlin). Primers used for amplification of complete coding regions for xIFoxP1 and XIFoxM1 are as follows:
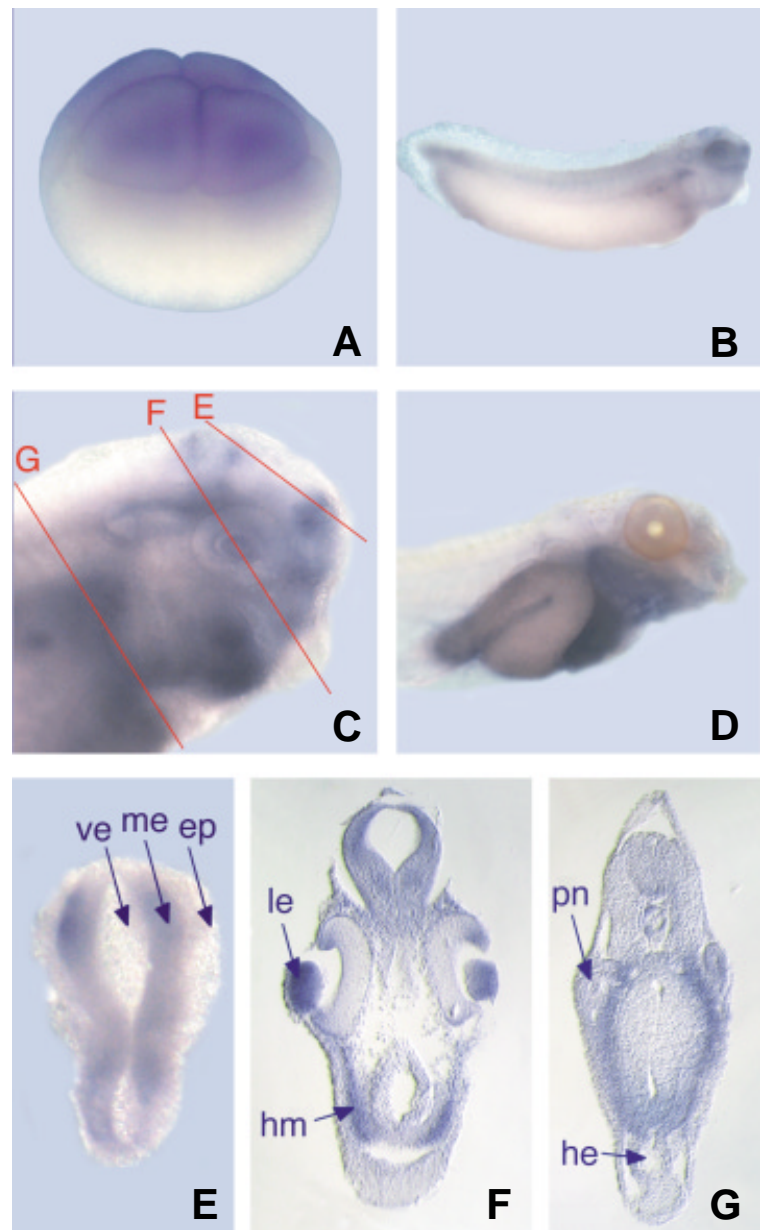

Fig. 6. Whole mount in situ hybridisation of $x$ IFoxP1. (A) 8-cell stage, lateral view; (B) stage 31; (C) stage 35, red lines in (C) indicate the plane of sections shown in (E-G); (D) stage 41, (B-D) are lateral views; (E) horizontal section, anterior is to the bottom; $(\mathbf{F}, \mathbf{G})$ transverse sections, dorsal is on top. ep, epidermis; he, heart; $h m$, head mesenchyme; le, lens; me, mesencephalon; pn, pronephros; ve, brain ventricle. 
xIFoxP1-for: 5'-CCC ACA AGA GGA ATG ACA AAC-3'; xIFoxP1-rev: 5'-TTA CTC CAT GTC GTC ATT TAC-3'; xIFoxM1-for: 5'-ATG CAT TTT GAG CTC TCA ATG-3'; xIFoxM1-rev: 5'-AGT TAA GAA TCT ACA GAA CAC TTG-3'.

Primers used in RT-PCR for temporal expression were xIFoxl2-RT-for: 5'-GAC AGC AGT CAC TGT TTC AC-3'; xIFoxl2-RT-rev: 5'-GGC CGA AGG GAT TCA TGA CAG-3'; xIFoxP1-RT-for: 5'-CAT GAT TCC AGC TGA ACT GC-3'; xIFoxP1-RT-rev: 5'-GCA CTC GAT ACT AGG TTC AG-3', xIFoxM1-RT-for: 5'-CCC AGA GTG TGC AAA GAT GG-3; xIFoxM1-RT-rev: 5'-TTC ACA CGC TTG CTG CTT T-3'.

\section{Acknowledgements}

We thank M. Köster and M.Schuff for screening of Xenopus CDNA libraries and $C$. Donow for help with in situ hybridisation. This work was supported by grants from the Deutsche Forschungsgemeinschaft (SFB 497/A3) and by Fonds der Chemischen Industrie.

\section{References}

BANHAM, A.H., BEASLEY, N., CAMPO, E., FERNANDEZ, P.L., FIDLER, C., GATTER K., JONES, M., MASON, D.Y., PRIME, J.E., TROUGOUBOFF, P., WOOD, K. and CORDELL, J.L. (2001). The FOXP1 winged helix transcription factor is a novel candidate tumor suppressor gene on chromosome 3p. Cancer Res. 61: 88208829.

COSTA, R.H., KALINICHENKO, V.V., HOLTERMAN, A.X. and WANG, X. (2003). Transcription factors in liver development, differentiation and regeneration. Hepatology 38: 1331-1347.

ENARD, W., PRZEWORSKI, M., FISHER, S.E., LAI, C.S., WIEBE, V., KITANO, T., MONACO, A.P. and PAABO, S. (2002). Molecular evolution of FOXP2, a gene involved in speech and language. Nature 418: 869-872.

KAESTNER, K.H., KNÖCHEL, W. and MARTINEZ, D.E. (2000). Unified nomenclature for the winged helix/forkhead transcription factors. Genes Dev. 14: 142-146.

KORVER, W., ROOSE, J. and CLEVERS, H. (1997a). The winged-helix transcription factor Trident is expressed in cycling cells. Nucleic Acids Res. 25: 1715-1719.

KORVER, W., ROOSE, J., HEINEN, K., WEGHUIS, D.O., DE BRUIJN, D., VAN KESSEL, A.G. and CLEVERS, H. (1997b). The human TRIDENT/HFH-11/ FKHL16 gene: structure, localization and promoter characterization. Genomics 46: 435-442.

KORVER, W., SCHILHAM, M.W., MOERER, P., VAN DEN HOFF, M.J., DAM, K., LAMERS, W.H., MEDEMA, R.H. and CLEVERS, H. (1998). Uncoupling of S phase and mitosis in cardiomyocytes and hepatocytes lacking the winged-helix transcription factor Trident. Curr. Biol. 8: 1327-1330.

LAI, C.S., FISHER, S.E., HURST, J.A., VARGHA-KHADEM, F. and MONACO, A.P. (2001). A forkhead-domain gene is mutated in a severe speech and language disorder. Nature 413: 519-523.

LEF, J., CLEMENT, J.H., OSCHWALD, R., KÖSTER, M. and KNÖCHEL, W. (1994). Spatial and temporal transcription patterns of the forkhead related XFD-2/XFD-2' genes in Xenopus laevis embryos. Mech. Dev. 45: 117-126.
LI, S., WEIDENFELD, J. and MORRISEY, E.E. (2004). Transcriptional and DNA binding activity of the Foxp1/2/4 family is modulated by heterotypic and homotypic protein interactions. Mol. Cell. Biol. 24: 809-822.

MORGENSTERN, B., FRECH, K., DRESS, A. and WERNER, T. (1998). DIALIGN: Finding local similarities by multiple sequence alignment. Bioinformatics 14:290294.

NIEUWKOOP, P.D. and FABER, J. (1967). Normal table of Xenopus laevis (Daudin), 2nd edn., Elsevier/North Holland, Amsterdam.

POHL, B.S. and KNÖCHEL, W. (2001). Overexpression of the transcriptional repressor FoxD3 prevents neural crest formation in Xenopus embryos. Mech. Dev. 103: 93-106.

POHL, B.S., KNÖCHEL, S., DILLINGER, K. and KNÖCHEL, W. (2002). Sequence and expression of FoxB2 (XFD-5) and Foxl1c (XFD-10) in Xenopus embryogenesis. Mech. Dev. 117: 283-287.

SCHLOSSER, G. and NORTHCUTT, R.G. (2000). Development of neurogenic placodes in Xenopus laevis. J. Comp. Neurol. 418: 121-146.

SHU, W., YANG, H., ZHANG, L., LU, M.M. and MORRISEY, E.E. (2001). Characterization of a new subfamily of winged-helix/forkhead (Fox) genes that are expressed in the lung and act as transcriptional repressors. J. Biol. Chem. 276: 27488-27497.

SOLOMON, K.S., LOGSDON, J.M., JR. and FRITZ, A. (2003). Expression and phylogenetic analyses of three zebrafish Foxl class genes. Dev. Dyn. 228: $301-$ 307.

TAMURA, S., MORIKAWA, Y., IWANISHI, H., HISAOKA, T. and SENBA, E. (2003). Expression pattern of the winged-helix/forkhead transcription factor Foxp1 in the developing central nervous system. Gene Expr. Patterns 3: 193-197.

WANG, B., LIN, D., LI, C. and TUCKER, P. (2003). Multiple Domains Define the Expression and Regulatory Properties of Foxp1 Forkhead Transcriptional Repressors. J. Biol. Chem. 278: 24259-24268.

WESTENDORF, J.M., RAO, P.N. and GERACE, L. (1994). Cloning of cDNAs for Mphase phosphoproteins recognized by the MPM2 monoclonal antibody and determination of the phosphorylated epitope. Proc. Natl. Acad. Sci. USA 91: 714718.

YAO, K.M., SHA, M., LU, Z. and WONG, G.G. (1997). Molecular analysis of a novel winged helix protein, WIN. Expression pattern, DNA binding property and alternative splicing within the DNA binding domain. J. Biol. Chem. 272: 19827-19836.

YE, H., KELLY, T.F., SAMADANI, U., LIM, L., RUBIO, S., OVERDIER, D.G., ROEBUCK, K.A. and COSTA, R.H. (1997). Hepatocyte nuclear factor $3 /$ fork head homolog 11 is expressed in proliferating epithelial and mesenchymal cells of embryonic and adult tissues. Mol. Cell. Biol. 17: 1626-1641.

Received: November 2004 Reviewed by Referees: November 2004 Modified by Authors and Accepted for Publication: January 2005 Edited by: Makoto Asashima 